Indonesian Journal of EFL and Linguistics

Vol. 2 No. 2, 2017

eISSN: 2503-4197, pISSN: 2527-5070

www. indonesian-efl-journal.org

\title{
CALL in Post-Method Era ${ }^{1}$
}

\author{
Hussien M. Abdo Almaktary \\ Higher Institute of Applied Languages and Computer Sciences, \\ Béja, Tunisia \\ e-mail: halmaktari2@gmail.com
}

\author{
Abdu M. Talib Al-Kadi \\ ISLT, Carthage University, Tunis \\ e-mail:findtalib@gmail.com
}

\begin{abstract}
:
This paper touches on the influx of technology in language learning and teaching with a focus on the post-method era. Scrutinizing this phenomenon within the framework of Computer-Assisted Language Learning (CALL) shows how technology has stimulated a transformation of language pedagogy from the traditional teachercentered and text-bound classrooms to student-centered and interactive paradigms. While the former paradigm is based on methodology, the latter is guided by principled eclecticism in which teachers make use of a set of macro-strategies so as to make decisions while teaching, instead of reliance on methods that dictate 'how to teach'. The teaching principles capitalize on teachers' sensitivity to local contexts rather than general methods. Though CALL has been mooted as panacea for ELT flaws in the method and post-method eras, it is not a one-size-fits-all model. Due to changeable and diversified technological innovations, it is impractical to adopt an electronic device or application for all contexts. Accordingly, the post-method pedagogy puts the onus on language teachers to make informed choices that best fit the particularity of their teaching situations.
\end{abstract}

Keywords: CALL; ELT; macro-strategies; method; post-method era

\footnotetext{
${ }^{1}$ The initial edition of this paper was presented in the INFOL@NGUES colloquium in Beja, Tunisia, organized in April 20-22, 2017.
} 


\section{INTRODUCTION}

Learning a non-mother tongue is not as easy as it might appear. It takes long time with sustained efforts to master a second or foreign language. Throughout the history of teaching methodology, numerous teaching methods have been suggested ranging from the grammar-translation method (1800) through the direct method (1900) and the audio-lingual method (1945) to the communicative language teaching (1980) and task-based language learning (1987). An escalation of other methods was patently evident especially in the $20^{\text {th }}$ century which witnessed a fever of methods some achieved wide recognition and acceptance at different decades while others faded away soon after they were recognized. Some were viewed as short-sighted (e.g. direct method) and others were deemed to be baggy and too general (e.g. the communicative approach). The rise and fall of methods was associated with the rise and fall of approaches and theories to language instruction (Richards \& Rodgers, 2001; Thornbury, 2009; Ur, 2015). Following certain methods, language teachers have developed different activities, games, and stories to make language teaching fun and encouraging. By the end of the century, a new teaching movement took over- the post-method era. Discussions on L2 instruction continue degrading the 'teaching methods'. The monopoly of a mono-method is no more accepted. At present, many researchers and pedagogues switch to 'teaching principles' (Richards, 2013).

What has been and is still evident in the method and post-method eras is the integration of technology (Khaloufi \& Laabidi, 2017; Laabidi, 2016; Motteram, 2013). It facilitates things which have been a desire. Even so, technological innovations change constantly and there has been no single technology tailored to all language teaching and learning contexts. Actually, incorporating technology into ELT has been an enduring fascination for decades, resulting in plenty of food for thought in several disciplines: sociolinguistics, psycholinguistics, education, etc. A number of claims were made in favor of technology-enhanced language learning (Kern, 2006; Watson, 2001; Zhao, Byers, Puge \& Sheldon, 2002). Such assertions maintain that technology supports different learning styles, provides a wealth of learning/teaching resources, and promotes independent learning. Nevertheless, there is still a flawed understating of the effectiveness of technology on L2 education in ESL or EFL contexts.

\section{OBJECTIVES}

This paper intends to ascertain different trends of technology-integration in ELT with a particular focus on computer-assisted language learning (CALL) and its associated allies. It highlights the phenomenon since the $1990 \mathrm{~s}$ - the period of method waning and beginning of the post-method era. The study brings to focus the principles upon which certain types of technology were adopted. It sketches a picture of technology-integrated language learning paradigm in an attempt to expand our understanding of its contributions to the cause of L2 education, and familiarize the language teachers-specially the novice- with the ongoing debate on the issue. The study also suggests new avenues for further research. 


\section{METHOD VS. NON-METHOD}

Language teaching is generally discussed within two broad phases: method and post method eras or -in simpler words- the method and non-method. Ur (2015) defines language methods as a series of classroom procedures based on a coherent set of learning or teaching principles which in their turn are based on theories of what language is and how it is learned. A given method is governed by views on language, L2 learning, goals and objectives of teaching, syllabus, teacher/learner's roles, activities, techniques and procedures (Richards, 2013; Thornbury, 2009). A teaching method is constructed of other elements. To Richards and Rodgers (2001), a method compromises approach, design, and procedures.

Although several methods have been proposed throughout the history of ELT, none could stand singly in all contexts. Ur (2015) enumerated four reasons that weakened the dominance of method. First, a particular method may not fit a local context, i.e. the local learners' needs, local culture, the personality of the teacher, and requirements of exams, etc. Second, enforcing procedures that teachers have to follow in a given method disempower teachers, preventing them from their right to decide how best to teach a particular class. Third, methods may lead to rejection of useful teaching and learning tools. Last- but equally important- a method may come to be taken as a goal in itself rather than a means to attain better outcomes. These reasons, among others, gave rise to the post-method pedagogy. Many writers have suggested this revolutionary phase of language teaching which contradicts 'method' in theory and practice (Ahmadi \& Maftoon, 2015; Akbari, 2008; Richards, 2013; Kumaravadivelu, 2001, 2006; Thornbury, 2009; Ur, 2015).

Inspired by poststructuralism, postmodernism, and post-colonialism, Kumaravadivelu (2006) argued that the 'post-method era' requires a deconstruction of the concept of 'method'. He invented a framework of ten macro-strategies derived from "available theoretical, empirical, and pedagogical knowledge related to L2 learning and teaching (p. 201); these macro-strategies are not based on assumptions of any specific language theory, learning, and teaching which characterize each method. Richards (2013) contends that these strategies encapsulate a set of core principles which are useful for teachers to make decisions while they teach. Richards argues that teaching is far more than simply a set of techniques learned from a book or training program. It is the teachers' own cognitively-based activity. Teachers in the post-method perspective are viewed as co-learners and researchers. The new buzz words of inspiration are 'innovation' and 'versatility' in lieu of the rigid methodological concept. The teaching principles of the post-method era, Richards postulates, derive from teacher training and experiences; teachers may also draw on their thinking and beliefs their own principles that service the basis for teaching practices. Similarly, Thornbury (2009) asserts that teaching is a process of creating learning opportunities and promoting not only the learner autonomy but also the teacher autonomy in light of such macro-strategies.

Putting it in the classroom context, the method-oriented pedagogy is a process of presentation and practice that lead to production while the post-method pedagogy accentuates the production itself (Akbari, 2008). That is, the concentration of the 
former is on the teacher following classroom procedures to achieve certain objectives and that of the latter is on the learners producing the language. For example, instead of teaching language communicatively as in the communicative approach, the focus of the post-method is the learners' communication. Another comparison is that the methods target language skills, which in many cases are isolated from contexts (de-contextualized) while teaching L2 in the post-method era is contextualized, i.e. language is necessarily taught in a context (Ur, 2015).

The post-method paradigm cannot be divorced from limitations. Kumaravadivelu's macro-strategies adopted in the place of 'procedures' resulted in limitations similar to those of the methods. For instance, some aspects of language need to be decontextualized such as teaching certain rules or jargons, etc. (Ur, 2015).

In spite of changing the status of method, the concept of 'teaching method' is still included in editions of new publications, teacher training programs, journal articles, recent conference/seminar presentations. Richards and Rodgers (2001) asserts that the concept of 'method' forms a significant component in teacher preparation programs for it provides teachers with a view of how language teaching has evolved as a field. Besides, teachers can adapt methods and approaches as a source of wellused practice (rather than prescriptions) to suit their own teaching contexts and needs. Moreover, the methodology provides teachers-especially novice teacherswith basic teaching skills to expand their own teaching repertoire.

\section{TECHNOLOGY-INTEGRATION}

Actually, infusing technology into language learning and teaching has undergone several stages, providing a tempting area of research. It was given impetus in the late1970s and early 1980s which is the period of real inception of computer-assisted language learning (CALL). It advanced to another station in the $1990 \mathrm{~s}$ - the period of internet applications (Chapelle, 2005). Turning into the twenty-first century, the cell phone with its features of mobility and space-restricted touch screen has taken the scene even further. Today language teachers and learners are familiar with a long list of technologies - language lab, interactive whiteboard (IWB), videos, webbased applications (e.g. blogs, wikis, Facebook) and there are many in the pipeline. Whereas the early technologies in the $20^{\text {th }}$ century were basically employed to convey and store data, the modern technologies have widened the spectrum of innovations by including emails, synchronous chat, asynchronous discussion groups, the many types of web-based tools; and the wonders of technology are continually on the rise.

This flood of technologies impacts language curricula, teaching methodology, and learning process. Technology- chiefly information and communication technology (ICT) -exposes learners to the real world with its complexity and brings it to language learning either in the classroom through audio-visual aids or online platforms. Motteram (2013) argued, "The language learning field is enhanced, but is also being changed, by the ways that technology is used by creative language teachers in the many different classrooms throughout the world" (p. 188). This is according to Brett (2001) because the ability to interact with language learning and communication elements via technology enables language learners to explore, 
discover, ponder, search, question, answer, and receive timely feedback.

\section{TECHNOLOGY INTEGRATION VS. TECHNOLOGY USE}

Generally, technology-integration is defined as the manipulation of any digital and internet-based technologies in language education. For the purpose of this study, integration refers to blending electronic language learning with L2 classroom teaching. In the literature, the term is sometimes distinguished from technology use. While integration implies the presence of preset/scheduled technologies, the term technology-use indicates utilizing technological tools and applications without obvious plans or primary intention to learn L2. In essence, both terms have a slight difference in meaning - they involve applications of technology. The concept of using or integrating technology in EFL/ESL learning and teaching is based on the review of relevant studies, defining it in terms of frequency of reiteration of technology uses on a daily basis. As it indicates purposeful usage, the term technology-integration is equated to CALL, and hereafter CALL is used interchangeably with technology-integration throughout this article.

Qin and Shuo (2011) suggested two main aspects when using technology in English instruction: (a) Technology as a tool for teaching English and (b) English is taught via technology. The authors postulated that English teachers and learners, in the former aspect, are aware that they use technology to support teaching and learning, particularly computers and the World Wide Web (WWW). A wide range of ICTs can be used as tools. For example, teachers and learners may use a word processor to correct, draft and redraft essays, other software to prepare lectures and presentations, and so forth. In such instances, attention is paid to technology itself. Technology awareness becomes a psychological burden and, in turn, it causes anxiety for them. In the latter aspect, the authors argued, technological facilities become an environment in which language materials and cross-cultural knowledge are presented; teachers and learners do not necessarily consider what software or hardware they need to process the language materials or present these materials; they basically focus on the target language and its culture.

\section{CALL RESEARCH}

As the term suggests, CALL is basically dependent on 'computer' as a delivery medium of applications. However, the term now is unexclusive to the 'canonical' desktop and laptop devices labeled computers but other possible technological facets that may be used in English education. In its broader definition today, CALL includes a number of innovations: PCs, mobile phones, electronic whiteboards, etc. These ICTs have a computer of different sorts embedded in them. This has been an area of research over the past century with several attempts to provide a CALL research framework. The capacious Computer-Assisted Language Learning (CALL) was the first term that came on board in the second half of the $20^{\text {th }}$ century. Other associated terms were coined later on: Internet-Assisted Language Learning (IALL), Technology-Enhanced Language Learning (TELL), and Mobile-Assisted Language Learning (MALL). However, CALL has no clear or specific theoretical background for language education; it depends mainly on theories of language acquisition.

Indonesian Journal of EFL and Linguistics, 2(2), 2017 
Egbert and Hanson-Smith (2000) argued that technology in language education is not based on a theory of its own but on language learning theories. This is supported by Miech, Nave and Mosteller's (1997) argument that "computers themselves do not possess theories of learning: Computer programmers and educators, consciously or unconsciously bring those theories to the task" (p. 61). Theories and models applied in the literature originate from previously established theories of learning, such as behaviorism, constructivism, etc. Hence, CALL research depends on not only SLA theory and practice but also computer science, instructional design, and humancomputer interaction. It is further complicated by the constant advancements in ICTs.

The acceleration of technological advancements and its vibrant uses in L2 contexts corresponds to developments of language learning approaches; every teaching method adopted specific technologies to support it. For instance, teachers who followed the grammar-translation method relied on blackboard (a perfect media for the one-way transmission of information) which was replaced by the overhead projector (OHP) later on. Again, OHP was another medium for the teacherdominated classroom. Afterward, the audio records were viewed as perfect tools for the audio-lingual method, which favored learning through oral repetition. In language education theory, there has been a shift from 'pedagogically-audiolingualism, psychologically-behaviorism, and linguistically-structuralism' towards social constructivism. It is boosted now by modern ICTs. This shift, according to Jarvis and Achilleos (2013), might be called "technology and task-based pedagogy" (p. 2).

Over the past decades, embedding technology in language education corresponded to SLA theoretical stages: behaviorist CALL, communicative CALL, integrative CALL, and intelligent CALL (iCALL). In each of these stages, various ICT devices and applications were used on the basis of developments in technology teaching paradigms, and pedagogical theories. The selection of ICTs served the purpose of a given approach (Davies, Otto \& Rüschoff, 2013).

\subsection{CALL in the Method Age}

The earliest CALL version (behaviorist CALL) coincided with the behavioristic theory of language learning. It came into existence in the 1960s and 1970s. Within the trenches of educational technology, behaviorist-learning theories were mainly associated with drill-and-practice applications, centered on repetitive language drills and games. Behaviorist CALL developed isolated and discrete competences, often, out of context. This drill-and-practice rehearsal was more effective with the help of mainframe computer. Language teachers who followed the grammar-translation method relied on the earliest type of technology. Later on, the OHP and early software computer programs were responsible for the provision of mechanical drilling. During the 1970s, when the audio-lingual method was at its zenith, students repeated monotonous pattern drills by using audiotaped materials in audio labs. Due to the incapability of language learners in responding to unrehearsed situations, the audio-lingual became peripheral by the end of 1970s. It waned in popularity due to lack of focus on communicative aspects of language use. 
The communicative CALL was viewed as a development over the behaviorist CALL. It saw the light of day in the 1980s when new personal computers created greater possibilities for individualized work. Corresponding to the cognitive theories, this stage used the target language predominantly and explicitly. A variety of software, simulating real life situations, was developed including text reconstruction programs that allowed students to rearrange words and discover patterns of meaning. The late 1980s and early 1990s witnessed a move toward communicative language teaching, which chiefly focused on students' engagement in real/ meaningful interaction. Besides using television, video tapes, audio cassettes, language labs, this period was the golden time of CD-ROMs and multimedia. This combination was expected to have substantial impacts on language learning. The communicative CALL assumes that humans are different - some students learn better by watching movies and listening to audios, and some learn better by reading or watching images, etc.

Although the communicative CALL was seen as an advance over the behaviorist CALL, linguists viewed it critically. Kenning and Kenning (1990) pointed out that the computer was used in a disconnected fashion and thus "finds itself making a greater contribution to marginal rather than central elements of the language learning process" (p. 90). Detractors of the communicative CALL argued that the focus was not so much on what students did with the machine but rather what they did with each other while working with computers. In addition, this approach stressed the importance of using computer-based activities to teach grammar implicitly and facilitate generating original utterances (rather than affected speech or manipulated prefabricated patterns) and use the target language predominantly or even exclusively (Gündüz, 2005).

Continued technology advancements and public uses of the Internet gave way to the integrative CALL (Gonzalez \& Louis, 2013). The emergence of cognitive and sociolinguistic approaches to language teaching in the 1980s and early 1990s along with an emphasis on student engagement with authentic meaningful and contextualized discourse instigated a shift in the use of technology in classrooms. This corresponded to a broader re-assessment of communicative language teaching theory and practice. Several attempts were made to move away from a cognitive view of communicative teaching to a more social or socio-cognitive view, which emphasized language use in authentic social contexts. Cognitive-constructivist approaches such as task-based learning, project-based, and content-based gradually found their match in digital technologies (Davies, Otto \& Rüschoff, 2013), i.e. integrating learners in authentic environments and integrating the skills of language learning and usage. The socio-cognitive approaches enhanced the use of language in authentic social contexts, and methodologies based on tasks (task-based), projects (project-based) or contents (content-based) aimed at the learner's autonomy of learning (Farivar \& Rahimi, 2015).

\subsection{CALL in the Post-Method Era}

The continuation of technological wonders brought to the foreground insightful ideas for language pundits, theorists, researchers, and teachers. The closure of the 
$20^{\text {th }}$ century witnessed language learning/teaching shifts, including the paradigm shift from method to post-method. It corresponded to the Integrative CALL which employs "a variety of technological tools as an ongoing process of language learning and use, rather than visiting the computer lab on a once a week basis for isolated exercises" (Warschauer \& Healey, 1998, 58). According to this approach, computers play the role of a tutor, providing "instruction, feedback, and testing in grammar, vocabulary, writing, pronunciation, and other dimensions of language and culture learning" (Kern, 2006, p.191), and teachers present formative and summative evaluation.

The twenty-first century which coincided with increasing uses of the Internet applications gave ground for Intelligent CALL (shortened as iCALL). It is a rebirth of CALL. In essence, it is an interdisciplinary field of research drawing on a number of disciplines in applied linguistics and computing (Blake, 2016; Gonzalez \& Louis, 2013). It applies concepts, techniques, algorithms, and technologies from artificial intelligence. In 1998, Warschauer and Healey envisaged the future of CALL. The authors envisioned two issues of it: electronic literacies and intelligent CALL. They discussed the latter exclusively in the context of online writing and tutorial CALL. That is, ICALL is a more structured, operationalized instructional environment than its precursor CALL. Owing to its sophisticated underlying technologies, ICALL added a new dimension to the traditional CALL environments.

The ICALL systems offer a wide variety of interactions. The arrival of Smartphones, tablets, and many other sophisticated appliances and was a real boon to language learners. The revival of the Web 1.0 (i.e. Web 2.0, Web 3.0) spawned new applications such as Twitter, Facebook, Skype, etc. Such electronic platforms extended potentials for worldwide communication. The multiplicity of ICTs has narrowed the 'digital divide' ${ }^{2}$ and facilitated ICT-based tasks even in low-tech environments (Gonzalez \& Louis, 2013). This phase fostered some aspects of modern language learning, such as acculturation, authenticity, and interaction. Compared to the previous phases of CALL, ICALL connects learners, instructors, and researchers with electronic language resources. The evolution of the WWW extended the roles of such users from accessing (Web 1.0), to contributing (Web 2.0) and innovations (Web 3.0). These technological advances have made possible to re-orient, re-create, and re-appropriate existing teaching materials, curricula and other relevant issues so as to fit within the post-method era.

\section{DISCUSSION}

The inflow of technology into L2 instruction has been evident in ELT yet it is constantly changing, chiefly due to two main reasons: (a) the evolution of technology itself and its ubiquity in everyday life, and (b) the changes of views on language learning- a move from the behaviorist to communicative and integrative learning perspectives and currently the most-method pedagogy. Guided by this change, teachers opt for different ICTs to help them achieve better results. The focus

\footnotetext{
2 'Digital divide' refers to the gap between those who have access to ICT and those who do not.
} 
is now on the outcomes of learning rather than the process of learning (Ur, 2015). Evidence from prior research demonstrated that ICTs promotes learner autonomy (Farivar \& Rahimi, 2015), gamification of the previous drill-and-kill principles (Lewis, 2015). It also directs focus on learners rather than teachers.

Although several studies were conducted on CALL in the post-method era, "research seems to be scattered across such a wide area that a specific picture of 'what CALL is and does' has not emerged" (Egbert, 2005, p. 3). However, it is now extensively used in SLA (Blake, 2016; Chapelle, 2005; Chun 2016). Technology is viewed now not only as motivational and assisting tools but essential appliances for language learning and teaching. The figure below illustrates the manipulation of technology in L2 pedagogy in the post-method era which corresponds to decreasing reliance on methods. In other words, the more the technology-integration, the less the method dominance becomes. In Lewis' (2015) words, the trendier the technology gets, the weaker the methodology becomes. We (the authors) think that a successful integration of technology requires a balance between pedagogy and technology, and a heavy reliance on 'methods' is unhealthy nowadays.

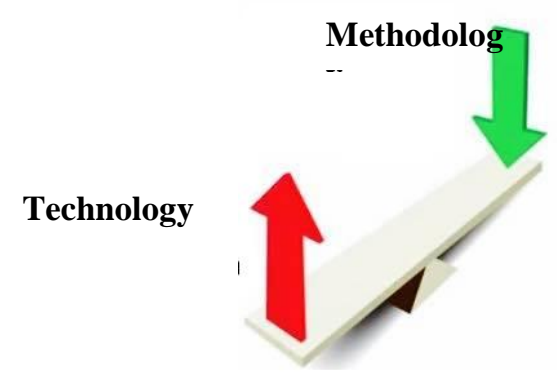

Fig. The Reverse Relationship between Methodology and Technology ${ }^{3}$

\subsection{Pedagogy before Technology}

Although CALL has played significant roles in language education for years, it is not a panacea for all problems in the field. The effectiveness of it, in practice, depends largely on the way it is handled (Blake, 2008; Khaloufi \& Laabidi, 2017; Chouit, Nfissi, Laabidi, 2017; Laabidi, 2016). Because ICTs are not always used for the activities they were originally intended for, educators innovatively re-appropriate such ICTs for learning/teaching purposes. For instance, the uses of mobile technologies, Sharples et al. (2009) argued, "may only be suitable for part of the activity, with other parts being better supported by other technologies, or by no technology at all” (p. 237). The majority of ICT tools and applications are generally described as multipurpose, multifunctional technologies that involve layers of complexity, and such technologies were not primarily invented for language teaching and learning purposes. Only a few of these tools were created specifically for learning purposes, e.g. data show projector and Interactive White Board (IWB).

\footnotetext{
3 adapted from Lewis (2015)
} 
Deciding what is best in any particular situation, Garrett (2009) argued, "will always require a teacher's considered analysis of that situation and detailed information on the... available options" (p.717). The selection is affected by (a) educators' understanding of the capacities of technology, (b) the real functions of technology and (c) educational goals and process.

Similarly, Garrett (2009) maintained that "the full benefit of CALL will not be realized until its use is fully integrated with classroom work on the basis of theoretically motivated research on the kinds of learning activities most enhanced by technology and those best undertaken without it" (p.702). Thus, using technology without clear vision is misleading with murky impacts. Watson (2001) and Motteram (2013) asserted that technology should be grounded in pedagogy to make it relevant and useful to the students' input, output and languaging. It should be based an overall blueprint guided by principled eclecticism.

\subsection{Limitations and Suggestions}

Although language is learned today through technology, the problem lies in the lack of straightforwardness of its integration in L2 situations, as discussed above. In Garrett's (2009) words, "there simply is no such thing as an ideal configuration of hardware or an ideal set of software for language learners in general, and there probably never will be" (p. 717). Actually, inadequate knowledge about ICT applications prevents teachers and learners from promoting higher-order cognitive skills which are difficult to address without technical aids. In the literature, little is known about integrating modern technologies within an overall plan of language learning and teaching (Chun, Kern \& Smith, 2016). It should be noted that CALL is not completely about computer literacy but language literacy. Sometimes, promising CALL models encounter technical challenges ensued from hardware and software limitations, and sometimes a lack of technical skills hampers successful CALL (Khaloufi \& Laabidi, 2017). In this regard, Zhao (2006) argued that the onus is on teachers to make informed choices of the technological devices and applications that they deploy in their teaching.

In the post-method paradigm, ELT through technology may be successful if anchored in macro-strategies that precisely define the language skills to be developed. Garrett (2009) assumed that "successful integration of technology will require new perspectives and new theory" (p. 714) rather than simply relying on haphazard technology uses. Some researchers found that a successful integration of ICT is more likely to happen when teachers' general pedagogical approach corresponds, in some way, to the characteristics of the technology (Garrett, 2009; Zhao, Pugh, Sheldon \& Byers, 2002). The techniques of incorporating cutting-edge ICTs into learning theories such as "constructivism" and "connectivism" need to be thoroughly researched "to ensure that tasks are suited to the affordances of the devices used" (Stockwell \& Hubbard, 2013, p. 3).

\section{CONCLUSION}

Method vs. post-method in ELT is an ongoing debate. This paper provides a general but recent outline of technology integration in ELT which gave way to what has 
been known as computer-assisted language learning and its allies. The most recent one is mobile-assisted language learning (MALL) - the mobility of learning and learners. Throughout the history of technology-based language learning, the various teaching methods matched "technological developments with pedagogical and methodological progress in language learning" (Davies, Otto \& Rüschoff, 2013, p. 34). The post-method era, which corresponds to MALL, TELL, and IALL has spawned new opportunities for learning beyond the classroom and rigid methods. Driven by the mobility of modern life, as well, language learning today is boundless to neither classroom nor textbooks. CALL enables learners nowadays to learn on their own more than what they learn in classrooms. This resulted in an array of concepts such as learner autonomy, informal and mobile learning, etc.

However, the concept of the method has not disappeared completely. While the post-method perspective has been accepted and practiced in some contexts, it has not received due attention in some others. Although the post-method era began in the 1990s and 2000s, overshadowing of the communicative and task-based language teaching still exists in many L2 contexts up till now (Akbari, 2008; Ahmadi \& Maftoon, 2015; T1ğl1, 2014, IV). Some methods may suit some context and certain aspects of the language. Although the post-method pedagogy requires teachers to break away from the past traditions, teachers still need to adopt theory-based teaching that facilitates achieving learning goals. Effective teaching in the postmethod pedagogy is based on eclectic approach (multiple methods) in order to keep things fresh for the learners and keep them stimulated and motivated. One of these encouraging techniques is the integration of technology which is the linchpin of most aspects of modern life. English instruction is now associated with computers, mobile devices, the Internet, etc. which are a daily practice. Exploring and measuring the effectiveness of modern technology on ELT have been an enduring fascination for decades, and is continuing.

The shifting paradigm in pedagogy underwent several phases during which different technologies were employed. Despite the contemporary incredible tech-innovations, it is seen now as in its earliest phase (Crystal, 2008). Based on what we can see around us and the development which is already underway, researchers predict that it will become even more so in the future. The WWW, for instance, is a creation from as recently as 1991 while the arrival of Facebook was not earlier than 2004. Crystal (2008) expected "further innovative developments especially of an interactive kind, which will push human languages in unexpected directions" (p. 406). Although ICT with its numerous electronic powerful tools has transformed the teacher-centered, text-bound classrooms into student-centered and interactive knowledge environments, it warrants further research to draw useful conclusions on how best harness technology within a well-defined framework (CALL) or maybe beyond CALL. 


\section{REFERENCES}

Ahmadi, A. \& Maftoon, P. (2015). Rethinking the language learner in the postmethod era: The question of identity. Procedia - Social and Behavioral Sciences, 192, 267_ 274. Doi: 10.1016/j.sbspro.2015.06.039

Akbari, R. (2008). Postmethod discourse and practice. TESOL Quarterly, 42, 641_652. Doi:10.1002/j.1545-7249.2008.tb00152.x

Blake, R. (2016). Technology and the four skills. Language Learning \& Technology, 20(2), 129-142.

Brett, P. (2001). The design, implementation and evaluation of a multimedia application for second language listening comprehension (Doctoral dissertation). University of Wolverhampton, Wolverhampton, UK.

Chapelle, C. (2005). Interactionist SLA theory in CALL research. In J. Egbert and G. Petrie, (Eds.), Research perspectives on CALL (pp. 53-64). Mahwah, NJ: Laurence Erlbaum Associates.

Chouit, D., Nfissi, A., Laabidi, H. (2017). Exploring the correlation between professors' use of ICT in teaching and the levels of institutional support. JELTL (Journal of English Language Teaching and Linguistics), 2(1), 47-63. doi:http://dx.doi.org/10.21462/jeltl.v2i1.39

Chun, D., Kern, R. \& Smith, B. (2016), Technology in language use, language teaching, and language learning. The Modern Language Journal, 100, 64-80. DOI: $10.1111 / \operatorname{modl} .12302$

Crystal, D. (2008).Texting. ELT J, 62 (1), 77_ 83. DOI:10.1093/elt/ccm08

Davies, G., Otto, S., \& Rüschoff, B. (2013). Historical perspectives on CALL. In M.Thomas, H. Reinders \& M. Warschauer (Eds.), Contemporary computerassisted language learning (pp. 19-35). London: Bloomsbury Academic.

Egbert, J. \& Hanson_ Smith, E. (Eds.) (2000).CALL environments: Research, practice, and critical issues. TESOL-EJ, 4(3). Retrieved from http://www.teslej.org/wordpress/issues/volume4/ej15/ej15r16/

Farivar, A. \& Rahimi, A. (2015). The impact of CALL on Iranian EFL learners' autonomy. Procedia- Social and Behavioral Sciences, 192, 644-649. Doi: 10.1016/j.sbspro.2015.06.112

Garrett, N. (2009). Technology in the service of language learning: Trends and issues. The Modern Language Journal, 93, 697-718. DOI: 10.1111/j.15404781.2009.00968.x

Gündüz, N. (2005). Computer assisted language learning (CALL). Journal of Language and Linguistic Studies, 1(2), 193_214.

Jarvis, H. \& Achilleos, M. (2013). From computer assisted language learning (CALL) to mobile assisted language use (MALU). The Electronic Journal for English as a Second Language(TESL-EJ),16(4), 1_ 18.

Khaloufi, A. \& Laabidi, H. (2017). An examination of the impact of computer skills on the effective use of ICT in the classroom. Indonesian Journal of EFL and Linguistics, 2(1), 53-69. DOI: 10.21462/ijefll.v2i1.29

Kenning, M. \& Kenning, M. J. (1990). Computers and language learning: Current theory and practice. New York: Ellis Horwood. 
Kern, R. (2006). Perspectives on technology in learning and teaching languages. TESOL Quarterly, 40(1), 183_ 210. Retrieved from http://dx.doi.org/10.2307/40264516

Kumaravadivelu, B. (2001). Toward a Postmethod Pedagogy. TESOL Quarterly, 35, 537_ 560. Doi:10.2307/3588427

Kumaravadivelu, B. (2006). Understanding language teaching: From method to postmethod. Lawrence Erlbaum Associates, Publishers Mahwah, New Jersey.

Laabidi, H. (2016). The effect of age on English professors' integration of the new technologies in teaching. IJELTAL (Indonesian Journal of English Language Teaching and Applied Linguistics), 1(1), 63-74.

Lewis, G. (2015). Reality check: Evaluating the impact of technology in language teaching 10 years after Web 2.0. Plenary Session 2 of the $5^{\text {th }}$ Bilgi University ELT Conference, May 9, 2015, Turkey.

Miech, E., Nave, B., \& Mosteller, F. (1997). On CALL: A review of computerassisted language learning in U.S. colleges and universities. Retrieved from ERIC, document production series No. ED 394525:1-115.

Motteram, G. (2013). Developing and extending our understanding of language learning and technology. In G. Motteram (Ed.), Innovations in learning technologies for English language teaching (pp. 177_ 191). London: the British Council.

Richards, J. C. \& Rodgers, T.S. (2001). Approaches and methods in language teaching. Cambridge: Cambridge University Press.

Richards, J.C. (2013). Curriculum approaches in language teaching: Forward, central, and backward design. RELC Journal, 44(1), 5_ 33.

Sharples, M., Arnedillo-Sanchez, I., Milrad, M., \& Vavoula, G. (2009). Mobile learning: Small devices, big issues. In N. Balacheff, S. Ludvigsen, T. Jong, A. Lazonder \& S. Barnes (Eds.), Technology enhanced learning: Principles and products (pp. 233_ 249). Heidelberg: Springer.

Stockwell, G. \& Hubbard, P. (2013). Some emerging principles for mobile-assisted language learning. Monterey, CA: The International Research Foundation for English Language Education. Retrieved from http://www.tirfonline.org/wpcontent/uploads/2013/11/TIRF_MALL_Papers_StockwellHubbard.pdf

Thornbury, S. (2009). Methods, post-method, and métodos. Retrieved from http://www.teachingenglish.org.uk/article/methods-post-methodm\%C3\%A9todos

Tiğl1, T. (2014). Method vs. postmethod: A survey on prospective EFL teachers' perspectives (MA thesis). The Graduate School of Education, Bilkent University.

Ur, P. (2015). Rethinking presentation-practice-production (PPP) in the post-method era. Plenary Session 4 of the $5^{\text {th }}$ Bilgi University ELT Conference, May 9, 2015, Turkey.

Warschauer, M. \& Healey, D. (1998). Computers and language learning: An overview. Language Teaching, 31(2), 57-71. DOI: 10.1017/S0261444800012970.

Watson, D. M. (2001). Pedagogy before technology: Re-thinking the relationship 
between ICT and teaching. Educational and Information Technologies, 6(4), 251_ 266. Kluwer Academic Publishers.

Zhao, Y., Byers, J. L., Puge, K., \& Sheldon, S. (2002). Conditions for classroom technology innovations. Teachers College Record, 104(3), 482 515. Retrieved from http://www.tcrecord.org/content.asp?contentid=10850

\section{Acknowledgments}

Thanks go to Dr. Bootheina Majoul and Dr. Faiza Derbel for their insightful ideas regarding technology integration in language pedagogy. 